\title{
Activities of Daily Living of Patients with Malignant Brain Tumors Assessed By Using Functional Independence Measurement Scoring System
}

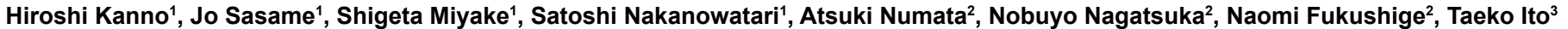
and Yoshimitsu Inoue ${ }^{2}$

${ }^{1}$ Department of Neurosurgery, Yokosuka City Hospital, Yokosuka, Japan

${ }^{2}$ Department of Rehabilitation, Yokosuka City Hospital, Yokosuka, Japan

\begin{abstract}
Patients with malignant brain tumors have varied degree of neurological impairments because of factors influencing activities of daily living (ADL). Those factors are related to characteristics of patients, tumor natures, and received treatment. However, factors influencing ADL of patients with malignant brain tumors are not fully elucidated. The functional independence measurement (FIM) is an ADL scoring system to determine impairment in different domains objectively. Here, we assessed ADL of 27 patients with malignant brain tumors at admission, discharge, 1 year and 2 years later using FIM scoring system, and identified factors influencing their ADL. In results, patient age and tumor pathology were identified as factors influencing ADL, while tumor site and operation type were not related to FIM scores. In conclusion, patient age and tumor pathology are identified as factors influencing ADL of patients with malignant brain tumors. Taking into account of those factors, neuro-rehabilitation program for patients with malignant brain tumors should be scheduled.
\end{abstract}

Keywords: FIM; Malignant brain tumor; Neurological impairment; Activities of daily living

Abbreviations: GBM: Glioblastoma; AA: Anaplastic Astrocytoma; AOA: Anaplastic Oligoastrocytoma; AO: Anaplastic Oligodendroglioma; CNSL: Central Nervous System Lymphoma; At/An Men: Atypical/ Anaplastic Meningioma; Mets: Metastatic Brain Tumor

\section{Introduction}

Malignant brain tumor affects approximate 14 per 100,000 populations annually [1], and the overall incidence of malignant brain tumor is increasing [2]. Patients with malignant brain tumors have varied degrees of functional and cognitive impairment either because of their tumors or the treatment that they receive. The impairments have been previously scored as mild, moderate or severe. Those scorings are relatively subjective, and are not always able to capture the accurate degree of improvement with intervention. With improved survival, the quality of life (QOL) becomes essential. If treatment for effective tumor control results in neurotoxicity with cognitive impairments and worse health-related QOL, longer survival may be less meaningful for patients. Proper information on health-related QOL and cognition on the long run might influence the choice of postoperative treatment. The purpose of neuro-rehabilitation for patients with malignant brain tumors not only improve activities of the daily living (ADL) but also maintain remaining functions to prevent disuse. However, factors influencing ADL of patients with malignant brain tumors are not fully elucidated [3]. Most of the ADL scores are easy to administer but do not capture cognitive data [4]. Although a few cooperative studies have successfully designed relatively easy to perform tests, it is not generally possible to carry out such evaluations in routine clinical practice. Functional independence measurement (FIM) is, on the other hand, a comprehensive tool to assess ADL activities, encompasses a few cognitive data and could be a useful and easy to-perform tool for rehabilitation assessment [5]. Here, we assess ADL of 27 patients with malignant brain tumors at admission, discharge, 1 year and 2 years later using FIM scoring system and identify factors influencing their ADL.

\section{Materials and Methods}

Twenty-seven patients (male, 14; female, 13) with malignant brain tumors [glioblastoma, 4; anaplastic asrtoctoma (AA)/anaplastic oligodendroglioma (AO)/ anaplastic oligoastrocytoma (AOA), 9; central nervous system lymphoma (CNSL), 5; metastatic brain tumor, 5; atypical/anaplastic meningioma (At/An Men), 4] were participants in this study. Their age ranged from 36 to 83 years, with the average 63.1 years). Characteristics of the participants were shown in Table 1. They admitted to Yokosuka City Hospital and underwent rehabilitation therapy as well as neurosurgical or medical treatment during August in 2011 to May in 2015. All participants had undergone neurosurgical intervention in the form of biopsy, partial removal, subtotal removal or a gross total removal and were referred to post operative treatment (radiotherapy, chemotherapy, supportive care, or all of these). Their statuses of ADL at admission, discharge, 1 year later, and 2 years later were assessed using functional independence measurement (FIM) score. The demographic profile including the age, sex, disease type, histopathological diagnosis, site, and symptoms at admission, neuroradiological findings and detailed clinical history with neurological findings were recorded after registration. The assessed domains in FIM scoring system included motor and cognitive domains. The motor item domains were classified into 13 subdomains and the cognitive item domains were classified into 5 subdomains described as Table 2. The highest score of each subdomain is 7 point while the lowest score is 1 point. The maximum total FIM score is 504 and the minimum 72. Motor item domains like self care, sphincter control, transfer, and locomotion domain, with their subdomains, were assessed by the questionnaire (Table 2) and also confirmed by examination $[5,6]$. Cognitive item domains include comprehension,

*Corresponding author: Hiroshi Kanno, Department of Neurosurgery, Yokosuka City Hospital, Yokosuka, Japan, Tel: 8146856 3136; E-mail: hiroshikannomd@nifty.com

Received May 04, 2015; Accepted June 13, 2015; Published June 20, 2015

Citation: Kanno H, Sasame J, Miyake S, Nakanowatari S, Numata A, et al. (2015) Activities of Daily Living of Patients with Malignant Brain Tumors Assessed By Using Functional Independence Measurement Scoring System. Int J Neurorehabilitation 2: 171. doi:10.4172/2376-0281.1000171

Copyright: @ $2015 \mathrm{Kanno} \mathrm{H}$, et al. This is an open-access article distributed under the terms of the Creative Commons Attribution License, which permits unrestricted use, distribution, and reproduction in any medium, provided the original author and source are credited. 
Citation: Kanno H, Sasame J, Miyake S, Nakanowatari S, Numata A, et al. (2015) Activities of Daily Living of Patients with Malignant Brain Tumors Assessed By Using Functional Independence Measurement Scoring System. Int J Neurorehabilitation 2: 171. doi:10.4172/23760281.1000171

Page 2 of 4

expression, social interaction, problem solving, and memory. These domains were assessed by using the questionnaire (Table 2) and verbal interaction with the participants [5,6]. Total FIM score, FIM motor score, and FIM cognition score were summed up with scores of all subdomains at admission, discharge, 1 year later, and 2 years later, and then those scores were statistically analyzed. Relation or correlation between FIM score and factors (age, tumor pathology, tumor site, and operation type) influencing activities of daily living (ADL) were statistically analyzed.

\section{Statistical analysis}

For comparisons between values for groups, the Schiff test after the ANOVA test was used, with probabilities of less than 0.05 being considered significant. For analysis of correlation between two groups, Pearson's correlation coefficient test was employed (Statcel version 5.0/7.0, California, USA).

\begin{tabular}{|c|c|c|c|}
\hline \multicolumn{4}{|l|}{ Sex } \\
\hline & Male & & 14 \\
\hline & Female & & 13 \\
\hline \multicolumn{4}{|l|}{ Age } \\
\hline & \multicolumn{2}{|l|}{ Mean age (years) } & 63.1 \\
\hline & \multicolumn{2}{|l|}{ Median (years) } & 63 \\
\hline & \multicolumn{2}{|l|}{ Stratum (years) } & \\
\hline & & $30-39$ & 2 \\
\hline & & $40-49$ & 3 \\
\hline & & $50-59$ & 4 \\
\hline & & $60-69$ & 8 \\
\hline & & $70-79$ & 6 \\
\hline & & $80-89$ & 4 \\
\hline \multicolumn{4}{|c|}{ Main symptom at onset } \\
\hline & \multicolumn{2}{|l|}{ Hemiparesis } & 15 \\
\hline & \multicolumn{2}{|l|}{ Speech disturbance } & 5 \\
\hline & \multicolumn{2}{|l|}{ Gait disturbance } & 2 \\
\hline & \multicolumn{2}{|l|}{ Cerebellar ataxia } & 2 \\
\hline & Headache & & 3 \\
\hline \multicolumn{4}{|c|}{ Histopathological diagnosis of tumor } \\
\hline & \multicolumn{2}{|l|}{ Glioblastoma } & 4 \\
\hline & \multicolumn{2}{|l|}{ Anaplastic astrocytoma } & 4 \\
\hline & \multicolumn{2}{|l|}{ Anaplastic oligoastrocytoma } & 4 \\
\hline & \multicolumn{2}{|l|}{ Anaplastic oligodendendroglioma } & 1 \\
\hline & \multicolumn{2}{|l|}{ Malignant CNS lymphoma } & 5 \\
\hline & \multicolumn{2}{|l|}{ Atypical meningioma } & 3 \\
\hline & \multicolumn{2}{|l|}{ Anaplastoc meningioma } & 1 \\
\hline & \multicolumn{2}{|l|}{ Metastatic brain tumor } & 5 \\
\hline \multicolumn{4}{|c|}{ Site of tumor } \\
\hline & \multicolumn{2}{|l|}{ Unilateral frontal region } & 10 \\
\hline & \multicolumn{2}{|l|}{ Bilateral frontal region } & 2 \\
\hline & \multicolumn{2}{|l|}{ Temporal region } & 4 \\
\hline & \multicolumn{2}{|l|}{ Parieto-occipital region } & 4 \\
\hline & \multicolumn{2}{|l|}{ Cerebellar region } & 2 \\
\hline & \multicolumn{2}{|l|}{ Brain stem/Thalamic region } & 5 \\
\hline \multicolumn{4}{|c|}{ Type of operation } \\
\hline & Biopsy only & & 6 \\
\hline & Partial removal & & 4 \\
\hline & Subtotal removal & & 6 \\
\hline & Gross total removal & & 11 \\
\hline
\end{tabular}

Table 1: Profile of participants with functional assessment done with FIM scoring system.

\begin{tabular}{|c|c|c|c|c|c|c|c|c|}
\hline Domains & & \multicolumn{7}{|c|}{ Disability level } \\
\hline \multicolumn{2}{|c|}{ Motor item domains } & \multicolumn{7}{|c|}{ Severe - - - - - - No } \\
\hline & Eating & 1 & 2 & 3 & 4 & 5 & 6 & 7 \\
\hline & Grooming & 1 & 2 & 3 & 4 & 5 & 6 & 7 \\
\hline & Bathing & 1 & 2 & 3 & 4 & 5 & 6 & 7 \\
\hline & Dressing-Upper Body & 1 & 2 & 3 & 4 & 5 & 6 & 7 \\
\hline & Dressing-Lower Body & 1 & 2 & 3 & 4 & 5 & 6 & 7 \\
\hline & Toileting & 1 & 2 & 3 & 4 & 5 & 6 & 7 \\
\hline & Bladder Management & 1 & 2 & 3 & 4 & 5 & 6 & 7 \\
\hline & Bowel Management & 1 & 2 & 3 & 4 & 5 & 6 & 7 \\
\hline & Transfers: Toilet & 1 & 2 & 3 & 4 & 5 & 6 & 7 \\
\hline & Transfers: Tub, Shower & 1 & 2 & 3 & 4 & 5 & 6 & 7 \\
\hline & Locomotion: Walk, Wheelchair & 1 & 2 & 3 & 4 & 5 & 6 & 7 \\
\hline & Locomotion: Stairs & 1 & 2 & 3 & 4 & 5 & 6 & 7 \\
\hline \multicolumn{2}{|c|}{ Cognitive item domains } & \multicolumn{7}{|c|}{ Severe - - . . . - No } \\
\hline & Comprehension & 1 & 2 & 3 & 4 & 5 & 6 & 7 \\
\hline & Expression & 1 & 2 & 3 & 4 & 5 & 6 & 7 \\
\hline & Social Interaction & 1 & 2 & 3 & 4 & 5 & 6 & 7 \\
\hline & Problem Solving & 1 & 2 & 3 & 4 & 5 & 6 & 7 \\
\hline & Memory & 1 & 2 & 3 & 4 & 5 & 6 & 7 \\
\hline
\end{tabular}

Table 2: Questionnaire of functional independence measurement (FIM).

\section{Results}

\section{FIM scores and their changes during admission to 2 years later}

Mean total FIM score of the entire patient population was $367.3 \pm$ 86.3 (range 217-501). The scores for motor and cognitive item domains were $267.5 \pm 65.5$ (range 33-91) and $100.2 \pm 23.3$ (range 15-32), respectively. Statistical analysis of differences in FIM scores of patients with malignant brain tumor at admission, discharge, 1 year and 2 years later revealed significant difference in those FIM scores (Table 3).

\section{Factors influencing ADL using FIM scoring system}

Patient age: Patient's age ranged from 36 to 83 years old. Correlation between total FIM scores and patient age was statistically analyzed by using Pearson's correlation coefficient test. The analyzed data revealed patient age was significantly reversely correlated with FIM motor item scores, FIM cognition item scores, and FIM total item scores (Table 4). This result indicated that patient age is a FIM-related influencing factor in malignant brain tumor patients. In particular, FIM scores of younger patients at both admission and discharge showed larger than those of older patients.

Tumor pathology: Total FIM scores, FIM motor item scores, and FIM cognition item scores in patients with malignant brain tumors were shown in Table 5. Relation between tumor pathology and FIM score was statistically analyzed. The analyzed data revealed a statistically significant difference between total FIM scores of patients with metastatic brain tumors and those with AA /AOA/AO, and also showed a significant difference between FIM motor item scores of patients with metastatic brain tumor and those with At/An Men.

Tumor site: Total FIM scores, FIM motor item scores, and FIM cognition item scores of patients in each tumor site were shown in Table 6. Relation between FIM score and tumor site was statistically analyzed. The analyzed data revealed no statistically significant relation between FIM score and tumor site.

Operation type: Total FIM scores, FIM motor item scores, and FIM cognition item scores of patients in each operation type were shown in 
Citation: Kanno H, Sasame J, Miyake S, Nakanowatari S, Numata A, et al. (2015) Activities of Daily Living of Patients with Malignant Brain Tumors Assessed By Using Functional Independence Measurement Scoring System. Int J Neurorehabilitation 2: 171. doi:10.4172/23760281.1000171

Page 3 of 4

\begin{tabular}{|l|c|c|c|c|c|c|}
\hline & Number of data & Mean & Unbiased variance & Standard deviation & Standard error & 3.4 \\
\hline FIM score at admission & 27 & 86.2 & 306.7 & 17.5 & 3.8 \\
\hline FIM score at discharge & 27 & 105.3 & 395 & 19.9 & 5.7 & \\
\hline FIM score at 1 year later & 27 & 98.6 & 864.5 & 29.4 & 2.7 \\
\hline FIM score at 2 years later & 27 & 75.4 & 1199.6 & 34.6 & 28.4 & P value \\
\hline Total FIM score & 108 & 91.4 & 805.5 & & F(0.95) \\
\hline \multicolumn{1}{|c|}{ Variable factor } & $\begin{array}{c}\text { Sum of deviation } \\
\text { squares }\end{array}$ & Degree of freedom & mean squares & F value & & \\
\hline Total variation & 86186.6 & 107 & & & 0.000283 & 2.692 \\
\hline Between-subgroup variation & 14279.4 & 3 & 4759.8 & 6.884 & & \\
\hline Error variation & 71907.2 & 104 & 691.4 & & \\
\hline
\end{tabular}

Table 3: ANOVA for FIM scores of patients with malignant brain tumor at admission, discharge, 1 year and 2 years later.

\begin{tabular}{|c|c|c|c|c|c|c|c|}
\hline & Number of data & $\begin{array}{l}\text { correlation } \\
\text { coefficient }\end{array}$ & $\mathrm{t}$ value & $\begin{array}{l}\mathrm{P} \text { value (Bilateral } \\
\text { probability) }\end{array}$ & $\mathrm{t}(0.975)$ & $95 \% \mathrm{Cl}$ lower & $95 \% \mathrm{Cl}$ upper \\
\hline Age, Adm-motor & 27 & -0.452 & -2.535 & 0.018 & 2.060 & -0.710 & -0.087 \\
\hline Age, DC-motor & 27 & -0.420 & -2.312 & 0.029 & 2.060 & -0.690 & -0.0472 \\
\hline Age, 1y-motor & 27 & -0.242 & -1.247 & 0.224 & 2.060 & -0.570 & 0.152 \\
\hline Age, 2yr-motor & 27 & 0.004 & 0.017 & 0.987 & 2.060 & -0.377 & 0.383 \\
\hline Age, total-motor & 27 & -0.277 & -1.442 & 0.161 & 2.060 & -0.595 & 0.115 \\
\hline Age, Adm-cognition & 27 & -0.488 & -2.797 & 0.010 & 2.060 & -0.732 & -0.133 \\
\hline Age, DC-cognition & 27 & -0.443 & -2.471 & 0.020 & 2.060 & -0.704 & -0.076 \\
\hline Age, 1y-cognition & 27 & -0.302 & -1.583 & 0.130 & 2.060 & -0.612 & 0.088 \\
\hline Age, 2 y-cognition & 27 & -0.212 & -1.082 & 0.289 & 2.060 & -0.548 & 0.183 \\
\hline Age,total-cognition & 27 & -0.392 & -2.131 & 0.043 & 2.060 & -0.672 & -0.014 \\
\hline Age, Adm-total & 27 & -0.495 & 0.009 & 0.009 & 2.060 & -0.736 & -0.142 \\
\hline Age, DC-total & 27 & -0.446 & -2.494 & 0.020 & 2.060 & -0.707 & -0.08 \\
\hline Age, 1y-total & 27 & -0.262 & -1.357 & 0.187 & 2.060 & -0.584 & 0.131 \\
\hline Age, 2y-total & 27 & -0.055 & -0.274 & 0.786 & 2.060 & -0.426 & 0.332 \\
\hline Age, all-total & 27 & -0.316 & -1.668 & 0.108 & 2.060 & -0.622 & 0.072 \\
\hline
\end{tabular}

Table 4: Correlation between patient age and FIM scores.

\begin{tabular}{|c|c|c|c|c|c|c|}
\hline Pathology & Number of data & Mean & Unbalanced variance & Standard deviation & Standard error & \\
\hline GBM & 4 & 372.3 & 3202.9 & 56.6 & 28.3 & \\
\hline AA/AOA/AO & 9 & 404.3 & 3511.3 & 59.3 & 19.8 & \\
\hline CNSL & 5 & 351.6 & 10044.3 & 100.2 & 44.8 & \\
\hline At/An Men & 4 & 420.0 & 7982.0 & 89.3 & 44.7 & \\
\hline Mets & 5 & 260.0 & 2392.0 & 48.9 & 21.9 & \\
\hline Total & 27 & 365.4 & 7447.8 & 86.3 & 16.6 & \\
\hline Variable factor & $\begin{array}{c}\text { Sum of deviation } \\
\text { squares }\end{array}$ & Degree of freedom & Mean squares & $\mathrm{F}$ value & $P$ value & $F(0.95)$ \\
\hline Total variation & 193642.5 & 26 & & & & \\
\hline Between-subgroup variation & 82252.6 & 4 & 20563.1 & 4.061 & 0.013 & 2.817 \\
\hline Error variation & 111389 & 22 & 5063.2 & & & \\
\hline
\end{tabular}

Table 5: ANOVA for relation between tumor pathology and FIM scores of patients with malignant brain tumors.

Table 7. Relation between FIM score and tumor site was statistically analyzed. The analyzed data showed no statistically significant relation between FIM score and operation type.

\section{Discussion}

In this study, we analyzed FIM scores of patients with malignant brain tumors. FIM system, used as a tool for assessment of rehabilitation program, is relatively simple to perform in routine clinical practice. Assessment using FIM are almost compatible with Barthel's index, the most widely used ADL evaluating system which has been validated in patients with neurological disability $[7,8]$. Our data revealed that patient age was reversibly correlated with their FIM scores. In particular, FIM scores of younger patients at admission and discharge showed larger than those of older patients. We speculated this result may well be due to the fact that older patients likely have more metastatic brain tumors. 
Citation: Kanno H, Sasame J, Miyake S, Nakanowatari S, Numata A, et al. (2015) Activities of Daily Living of Patients with Malignant Brain Tumors Assessed By Using Functional Independence Measurement Scoring System. Int J Neurorehabilitation 2: 171. doi:10.4172/23760281.1000171

Page 4 of 4

\begin{tabular}{|c|c|c|c|c|c|c|}
\hline Tumor region & Number of data & Mean & Unbalanced variance & Standard deviation & Standard error & \\
\hline Unilateral Frontal & 10 & 290 & 3422.9 & 58.5 & 18.5 & \\
\hline Brainstem/thalamus & 5 & 258.6 & 3857.3 & 62.1 & 27.8 & \\
\hline Temporal & 4 & 265.8 & 5494.9 & 74.1 & 37.1 & \\
\hline Parietal/ Occipital & 4 & 276.8 & 4204.3 & 64.8 & 32.4 & \\
\hline Bilateral Frontal & 2 & 218 & 6962 & 83.4 & 59 & \\
\hline Cerebellar & 2 & 171 & 288 & 17 & 12 & \\
\hline Total & 27 & 264.5 & 4295.2 & 65.5 & 12.6 & \\
\hline Variable factor & $\begin{array}{c}\text { Sum of deviation } \\
\text { squares }\end{array}$ & Degree of freedom & Mean squares & F value & $P$ value & $F(0.95)$ \\
\hline Total variation & 111674.7 & 26 & & & & \\
\hline Between-subgroup variation & 29092.04 & 5 & 5818.4 & 1.48 & 0.239 & 2.685 \\
\hline Error variation & 82582.7 & 21 & 3932.5 & & & \\
\hline
\end{tabular}

Table 6: ANOVA for relation between FIM scores of malignant brain tumor patients and tumor sites.

\begin{tabular}{|c|c|c|c|c|c|c|}
\hline & Number of patients & Mean & Unbalanced variance & Standard deviation & Standard error & \\
\hline Biopsy only & 6 & 384 & 5823.2 & 76.3 & 31.2 & \\
\hline Partial removal & 4 & 405 & 5328.7 & 73 & 36.5 & \\
\hline Subtotal removal & 6 & 359 & 3718.4 & 61 & 24.9 & \\
\hline Gross total removal & 11 & 344.4 & 11648.7 & 107.9 & 32.5 & \\
\hline Total & 27 & 365.4 & 7447.8 & 86.3 & 16.6 & \\
\hline Variable factor & $\begin{array}{c}\text { Sum of deviation } \\
\text { squares }\end{array}$ & Degree of freedom & Mean squares & $F$ value & $P$ value & $F(0.95)$ \\
\hline Total variation & 193642.5 & 26 & & & & \\
\hline Between-group variation & 13462 & 3 & 4487.3 & 0.573 & 0.639 & 3.028 \\
\hline Error variation & 180180.5 & 23 & 7833.9 & & & \\
\hline
\end{tabular}

Table 7: ANOVA for relation between operation types and FIM scores of patients with malignant brain tumors.

This means older patients are likely to have considerably more deficits in some domains than their younger counterparts, irrespective of the history of their brain tumors. In addition, our data revealed FIM scores of patients with malignant brain tumors were related to tumor pathologies. In patients with metastatic brain tumors, total FIM scores were significantly worse than those of patients with AA/AOA/AO. Similarly, their FIM motor item scores were significantly worse than those of patients with At/An Men. Motor functions were relatively more impaired by frontal /parietal lobe lesions affected by metastatic brain tumors. In contrast, FIM motor domain item scores of patients with At/An Men might be preserved because of the regions from where At/An Men arose. On the other hand, tumor sites and operation types were not recognized as factors influencing ADL. However, those results might change if small number of participants becomes larger. In the future, a study with a larger number of participants would be necessary.

In conclusion, this study showed that factors influencing ADL of patients with malignant brain tumors are age of patients and tumor pathology. Taking into account of those factors, neuro-rehabilitation program for patients with malignant brain tumors should be scheduled.

\section{References}

1. Committee of Brain Tumor Registry of Japan (2010) Report of Brain Tumor Registry of Japan. Neurol Med Chir 54: 1-102.

2. Flowers $A$ (2000) Brain tumors in the older person. Cancer Control 7: 523-538.

3. Dutta D, Vanere P, Gupta T, Munshi A, Jalali R (2009) Factors influencing activities of daily living using FIM-FAM scoring system before starting adjuvant treatment in patients with brain tumors: Results from a prospective study. $J$ Neurooncol 94: 103-110.

4. Khan F, Amatya B, Drummond K, Galea M (2014) Effectiveness of integrated multidisciplinary rehabilitation in primary brain cancer survivors in an Australian community cohort: A controlled clinical trial. J Rehabil Med 46:754-760

5. Heinemann AW, Linacre JM, Wright BD, Hamilton BB, Grander CV (1993) Relationships between impairment and physical disability as measured by the functional independence measure. Arch Phys Med Rehabil 74: 566-573.

6. Kidd D, Stewart G, Baldry J, Johnson J, Rossiter D, et al., (1995) The functional independence measure: a comparative validity and reliability study. Disabil Rehabil 17: 10-14

7. Brazil L, Thomas R, Laing R, Hines F, Guerrero D, et al (1997) Verbally administered Barthel index as functional assessment in brain tumor patients. J Neurooncol 34: 187-192.

8. Sardell S, Sharpe G, Ashley S, Brada M (2000) Evaluation of a nurse-led telephone clinic in the follow-up of patients with malignant glioma. Clin Oncol 12: 36-41 